\title{
COMPLICATIONS AND COST ANALYSIS OF HEMIPELVECTOMY FOR THE TREATMENT OF PELVIC TUMORS
}

\author{
COMPLICAC̣ÕES E ANÁLISE DE CUSTO DA HEMIPELVECTOMIA \\ PARA O TRATAMENTO DE TUMORES DA PELVE
}

\author{
Mariana Tedeschi Benatto ${ }^{1}$, Amira Mohamede Hussein ${ }^{1}$, Nelson Fabricio Gava ${ }^{2}$, Daniel Augusto Maranho ${ }^{2}$, Edgard Eduard Engel ${ }^{2}$ \\ 1. Universidade de São Paulo, Faculdade de Medicina de Ribeirão Preto, Hospital Clínica de Ribeirão Preto, Centro de Reabilitação, Ribeirão Preto, SP, Brazil. \\ 2. Universidade de São Paulo, Faculdade de Medicina de Ribeirão Preto, Departamento de Biomecênica, Medicina e Reabilitaçaõ do Sistema Locomotor, Ribeirão Preto, SP, Brazil.
}

\section{ABSTRACT}

Objective: Hemipelvectomy is a complex surgery with a high complication rate. Here, we aimed to identify factors related to the onset of complications and calculate their impacts on hospital costs. Methods: We evaluated 31 consecutive patients who underwent hemipelvectomy between 1999 and 2015. We assessed the clinical and radiographic data to determine the patients' demographic factors, tumor and surgical characteristics, and complications. The individual hospital stays and financial balances were assessed up to 6 months following the index surgery. Results: The overall complication rate was $61 \%$ (19/31). Infection was the most prevalent complication (36\%). Immediate postoperative death occurred in 5/31 patients (16\%); another 5 (16\%) died after hospital discharge due to disease progression. Histological grade, previous surgery, and previous radiotherapy were not associated with complications or infection. Acetabular resections, bone reconstruction, and longer operative times were associated with infection, whereas older age, pelvic organ involvement, and comorbidities were associated with immediate postoperative death. Complications and infection were associated with 4.8- and 5.9-fold increases in hospital costs, respectively. Conclusions: Acetabular resection and bone reconstruction are important factors that increase short-term complication rates, infection rates, and hospital costs. Mortality was associated with older age and adjacent pelvic tumor progression. Level of Evidence: IV, case series.

Keywords: Bone neoplasm, Hemipelvectomy, Patient outcome assessment, Cost analysis, Pelvic neoplasm.

\section{RESUMO}

Objetivo: Hemipelvectomia é uma cirurgia complexa associada a alta taxa de complicações. O objetivo foi identificar fatores relacionados a complicações e calcular o impacto sobre os custos hospitalares. Métodos: Avaliamos 31 pacientes consecutivos submetidos à hemipe/vectomia entre 1999 e 2015. Analisamos dados clínicos e radiográficos para determinar variáveis demográficas, características do tumor e cirurgia, e complicações. A internação hospitalar individual e o balanço financeiro foram calculados até seis meses após a cirurgia principal. Resultados: A taxa de complicações foi de 61\% (19/31). Infecção foi a complicação mais frequente (36\%). Morte pós-operatória precoce foi observada em 5/31 pacientes (16\%) e outros cinco (16\%) morreram após alta hospitalar devido à progressão da doença. Grau histológico, cirurgia e radioterapias prévias não estiveram associadas com complicações ou infecções. Ressecções acetabulares, reconstruções ósseas e maiores tempos cirúrgicos estiveram associados com infecções, enquanto que mais idade, envolvimento de orgão pélvico e comorbidades estiveram associados com morte precoce. Complicações e infecções apresentaram aumento de 4,8-, e 5.9-vezes nos custos hospitalres. Conclusões: Ressecções acetabulares e reconstrução óssea são fatores importantes que aumentam as complicações, infecções e custos hospitalares. Mortalidade está associada com maior idade e progressão tumoral intrapélvica. Nível de Evidência IV, Série de casos.

Descritores: Neoplasias ósseas. Hemipelvectomia. Avaliação de Resultados da Assistência ao Paciente. Custos e Análise de custo. Neoplasias Pélvicas.

Citation: Benatto MT, Huss ein AM, Gava NF, Maranho DA, Engel EE. Complications and cost analysis of hemipelvectomy for the treatment of pelvic tumors. Acta Ortop Bras. [online]. 2019;27(2):104-7. Available from URL: http://www.scielo.br/aob.

\section{INTRODUCTION}

Primary tumors of the pelvis are complex conditions that may require aggressive treatment. Chondrosarcoma is the most frequent primary tumor of the pelvis, followed by Ewing's sarcoma and osteosarcoma., ${ }^{1,2}$ Pelvic tumors present less favorable prognosis compared to long bone tumors. ${ }^{2}$
Pelvic tumors are generally large at diagnosis, and the therapeutic decision-making is challenging because of the contiguous neurovascular structures, intestinal tract and urinary tract. ${ }^{1,3-5}$ The proportion of external hemipelvectomies has decreased in recent decades, following the same trend of limb salvage that is applied for the current treatment of long bone tumors. ${ }^{6}$ Despite a considerable decrease in the mortality rate,

All authors declare no potential conflict of interest related to this article.

The study was conducted at the Clinical Hospital of the Ribeirão Preto Medical School, University of São Paulo, Ribeirão Preto, SP, Brazil.

Correspondence: Edgard E Engel, Department of Biomechanics, Medicine, and Rehabilitation of the Locomotor System, Ribeirao Preto Medical School, University of Sao Paulo. Av. Bandeirantes, 3900, 11 의oor, Ribeirao Preto, SP, Brazil. 14049-090. engel@fmrp.usp.br 
which is currently between 0 and $10 \%$, the complication rate remains very high, between 30 to $80 \%$. Wound infection, flap necrosis, reconstruction failures (aseptic loosening, fractures, pseudarthrosis), nerve lesions, thrombosis, viscera injuries and functional disability have been frequently reported. ${ }^{3-8}$ Infection is the most common postoperative complication, varying between $20 \%$ and $80 \% .^{3,4}$ Older age, prolonged operative time, poor flap viability and the type of reconstruction are factors associated with complications. , $^{1,3,4}$

Cost analyses of hemipelvectomies are poorly reported in the literature, and a study detailing the complication rate and costs may provide useful information for specialized oncologic centers. The impact of several factors, such as implant requirements, hospitalization in intensive care units and the characteristics of the complications are of utmost importance to the financial balance. The objectives of this study were to (a) analyze the risk factors that might influence the rate of complications, infection and death and (b) perform a cost analysis of a series of patients affected by pelvic tumors who were treated with hemipelvectomy in a single institution funded by the public health system.

\section{MATERIALS AND METHODS}

This is a retrospective study approved by the Institutional Review Board (CAAE: 47355415.0.0000.5440), with waiver of informed consent. We included 31 consecutive patients who underwent hemipelvectomy as index surgical treatment for the treatment of primary pelvic tumors from January 1999 and July 2015. Clinical and imaging data were reviewed from the preoperative up to the first six postoperative months following hemipelvectomy. There were 17 men and 14 women with a median age of 46 years (ranging from nine to 79). We assessed patient demographic characteristics (age and sex), diagnosis (tumor grade and pelvic organ involvement), risk factors (body mass index, hypertension, diabetes, previous radiation therapy, chemotherapy or surgery, and tobacco use), type of surgery (internal or external hemipelvectomy, resection classification, bone reconstruction, pelvic organ reconstruction, operative time, and need for blood transfusion), hospitalization length (ward and intensive care hospitalization days) and final status (resolution of complications, number of reoperations and need for conversion to external hemipelvectomy) (Table 1). We further evaluated the main variables including (a) the presence of complications, which included early death, infection, bowel fistula, abdominal wall hernia, and renal insufficiency; (b) the presence of postoperative infection, which included deep infection, dehiscence, and flap necrosis; (c) early or late death, and (d) the estimated financial balance. Immediate postoperative death was considered an inpatient event, and late death was considered after the hospital discharge.

The most frequent histological type was chondrosarcoma (seven cases), followed by Ewing's sarcoma (five cases) and osteosarcoma (four cases). Sixteen tumors were classified as high grade. The involvement of pelvic organs occurred in 12 patients, and the bladder was the most frequently affected organ (four cases, 13\%), followed by the rectum (three cases, 10\%). Seventeen hemipelvectomies were internal, and 14 were external (55\% and $45 \%$, respectively). Resections were classified according to the Enneking and Dunham classification. ${ }^{9}$ The most common type was I + II + III (29\%), followed by type III (19\%) and type II + III (13\%). In nine cases (29\%), some type of bone reconstruction was required: endoprosthesis alone in two cases, fibular graft in one, and a polypropylene mesh alone in three. The polypropylene mesh was combined with endoprosthesis in two additional cases and with fibular graft in one additional case. The fibular graft was used to reconstruct the pelvic ring. The polypropylene mesh was used to reconstruct the abdominal wall or to attach the endoprosthesis to the remaining bone when hip medialization was performed (Figure 1). The median operative time was six hours, ranging from 1.4 to 22.3 hours. Blood transfusion, with a median of 3 units ( $1-6$ units) was needed for 22 patients and

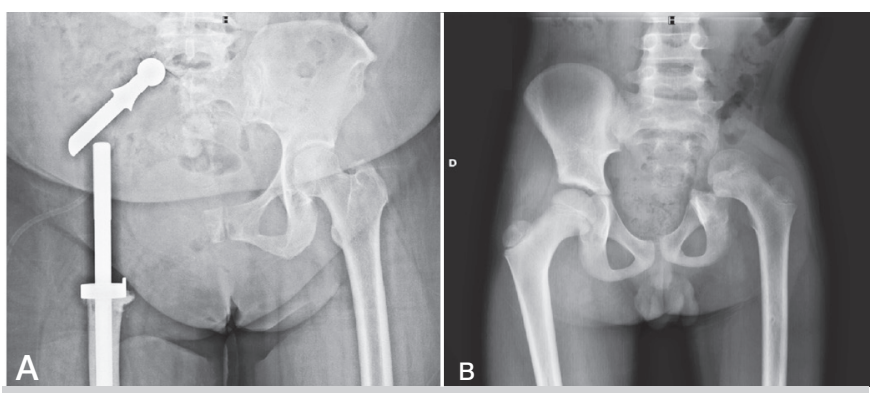

Figure 1. Reconstruction alternatives. Hip medialization technique with a polyethylene proximal femur prosthesis was used to reconstruct a I - IV pelvic resection in an adult patient (A). No bone reconstruction was used after a I + II pelvic resection in a pediatric patient.

Table 1. Medians, ranges and p-values of groups with and without complications, infections and death.

\begin{tabular}{|c|c|c|c|c|c|c|c|c|c|c|}
\hline & \multicolumn{3}{|c|}{ General complication } & \multicolumn{2}{|c|}{ Infection } & \multicolumn{4}{|c|}{ Death } & \multirow[b]{2}{*}{$p$ value } \\
\hline Demographics & Without ( $n=12)$ & With $(n=19)$ & $p$ value & Without $(\mathrm{n}=20)$ & With $(n=11)$ & $p$ value & Alive $(n=21)$ & Early death $(n=5)$ & Late death $(n=5)$ & \\
\hline Age (years) & $35(9-58)$ & $51(20-79)$ & .01 & $45(27-58)$ & $48(41-61)$ & .42 & $43(9-71)$ & $65(48-69)$ & $46(26-79)$ & .02 \\
\hline Sex (male) & $7(58 \%)$ & $10(53 \%)$ & .76 & $10(50 \%)$ & $7(64 \%)$ & .7 & $11(52 \%)$ & $3(60 \%)$ & $3(60 \%)$ & .76 \\
\hline \multicolumn{11}{|l|}{ Diagnosis } \\
\hline Histologic grade (high) & $11 / 11(100 \%)$ & $12 / 16(75 \%)$ & .07 & $15 / 17(88 \%)$ & $8 / 10(80 \%)$ & .56 & $15 / 19(79 \%)$ & $3 / 3(100 \%)$ & $5 / 5(100 \%)$ & .38 \\
\hline Pelvic organ involvement & $1(8 \%)$ & $10(53 \%)$ & .012 & $(30 \%)$ & $5(45 \%)$ & .39 & $5(24 \%)$ & $4(80 \%)$ & $2(40 \%)$ & .02 \\
\hline \multicolumn{11}{|l|}{ Risk factors } \\
\hline Weight (kg) & $67(25-90)$ & $77(33-121)$ & .15 & $66(58-1)$ & $8(68-80)$ & .16 & $68(25-121)$ & $82(65-95)$ & $71(33-99)$ & .21 \\
\hline Comorbidities & $2(18 \%)$ & $10(53 \%)$ & .06 & $7(37 \%)$ & $5(45 \%)$ & .64 & $5(25 \%)$ & $4(80 \%)$ & $3(60 \%)$ & .02 \\
\hline Previous radiotherapy & $2(18 \%)$ & $4(22 \%)$ & .80 & $3(16 \%)$ & $3(30 \%)$ & .37 & $5(26 \%)$ & $1(20 \%)$ & 0 & .77 \\
\hline Previous chemotherapy & $7(64 \%)$ & $6(33 \%)$ & .11 & $9(47 \%)$ & $4(40 \%)$ & .71 & $8(42 \%)$ & $1(20 \%)$ & $4(80 \%)$ & .36 \\
\hline Previous surgery & 0 & $3(16 \%)$ & .18 & $1(6 \%)$ & $2(18 \%)$ & .28 & $2(11 \%)$ & 0 & $1 / 5(20 \%)$ & .45 \\
\hline Smoker & 0 & $7(37 \%)$ & .046 & $3(19 \%)$ & $4(36 \%)$ & .31 & $4(22 \%)$ & $2(40 \%)$ & $1(25 \%)$ & .42 \\
\hline \multicolumn{11}{|l|}{ Surgery } \\
\hline Internal hemipelvectomy & $8(67 \%)$ & $(47 \%)$ & .29 & $11(55 \%)$ & $6(55 \%)$ & .98 & $16(76 \%)$ & 0 & $1 / 5(20 \%)$ & .002 \\
\hline At least type II classification & $6(50 \%)$ & $14(74 \%)$ & .18 & $10(50 \%)$ & $10(91 \%)$ & .02 & $12(57 \%)$ & $4(80 \%)$ & $4(80 \%)$ & .35 \\
\hline Bone reconstruction & 0 & $9(47 \%)$ & .005 & $1(5 \%)$ & $8(73 \%)$ & .001 & $7(33 \%)$ & $1(20 \%)$ & $1(20 \%)$ & .56 \\
\hline Pelvic organ reconstruction & 0 & $4(21 \%)$ & .09 & $2(10 \%)$ & $2(18 \%)$ & .52 & $2(10 \%)$ & $2(40 \%)$ & 0 & .090 \\
\hline Operative time (hours) & $3(2-7)$ & $9(4-23)$ & .001 & $5(3-7)$ & $10(6-14)$ & .002 & $5(2-23)$ & $8(6-16)$ & $9(7-14)$ & .073 \\
\hline Blood transfusion (units) & $2(0-4)$ & $2(0-6)$ & .70 & $2(0-3)$ & $1(1-2)$ & .48 & $1(0-5)$ & $3(2-6)$ & & .12 \\
\hline
\end{tabular}


unnecessary for five patients. We could not retrieve specific details for the other four patients. The median hemoglobin concentration was $10.4 \mathrm{~g} / \mathrm{dL}(5.0$ - 15.0) at the beginning and $9.5 \mathrm{~g} / \mathrm{dL}(4.1-12.4)$ at the end of surgery.

A cost analysis was conducted by the institutional financial center for each patient. The expenses of the ward and intensive care unit, operative room (OR), post-anesthesia care unit, medications, surgical implants and blood products were analyzed separately. OR and inpatient daily expenses were estimated from average hospital balances. Medical fees were not included.

For descriptive statistical analysis, the categorical variables were expressed as frequency and percentage, whereas the continuous variables were expressed as median and range. Groups with or without complications or infection, and who were alive or not were compared with chi-squared tests for categorical variables and Mann-Whitney $U$ tests for continuous variables. PASW software version 17 (IBM SPSS, Armonk, USA) was used for data analysis, and $p$-values $>0.05$ were considered significant.

\section{RESULTS}

\section{Complications}

Complications were found in 19 of 31 patients (61\%) (Table 1). Eleven patients had deep infections or flap necrosis, and one of them died due to multiple organ failure. Two patients had abdominal organ herniations, one had renal insufficiency, and another two had bowel fistulizations (one death). Another three patients died due to multiple organ failure.

Higher complication rates were related to older patients $(p=0.01)$, pelvic organ involvement $(p=0.01)$, tobacco use $(p=0.046)$, bone reconstruction $(p=0.01)$, and operative time $(p=0.001)$.

\section{Infection}

Infection was the most common complication (11 of 31; 36\%). Deep infection occurred in nine patients (29\%) and two patients had flap necrosis and dehiscence (7\%) (Table 1). The overall strategy for infection treatment was based on debridement in the operating room and intravenous antibiotics, with a control rate of $89 \%$. In only one of 11 patients, infection could not be controlled within six months after surgery.

The infection rate was significantly high for the longer surgeries $(p=0.002)$, when bone reconstruction was needed (Table 2) $(p=0.001)$ and when at least the acetabulum was resected (type II hemipelvectomy) $(p=0.023)$.

\section{Death}

Ten of 31 patients (32\%) died within the six-month postoperative period (Table 1). An early mortality rate of $16 \%$ (five patients) was observed after a median time of 29 days $(13-88)$ after surgery. The late mortality rate, after hospital discharge, was also 16\% (five patients) as a consequence of tumor progression.

Early death was significantly high for older patients $(p=0.02)$, pelvic organ tumor involvement $(p=0.02)$ and patients who underwent external hemipelvectomies $(p=0.034)$. Thirteen patients $(42 \%)$ had prior disease (including hypertension [11 cases] and diabetes mellitus [five cases]), and these comorbidities were associated with early death $(p=0.02)$.

\section{Cost analysis}

The median postoperative hospital inpatient stay was 15 days and ranged from 2 to 141 days. The presence of complications increased the median hospital stay from 7 days $(2-22)$ to 38 days $(9-141)$ $(p=0.001)$. Specifically, infection increased the median hospital stay from 9 (2-109) to 40 days (10-141) $(p=0.002)$.

The median cost was $\mathrm{R} \$ 15,517.81$ and ranged from $\mathrm{R} \$ 3,162.99$ to $\mathrm{R} \$ 87,970.99$. The presence of complications led to a 4.8 -fold increase in the median total costs $(p=0.000)$, whereas infection led to a 5.9-fold increase in the median total costs $(p=0.001)$. The median cost was increased by 2.1 for the early death patients $(p=0.16)$ (Table 3). Bone reconstruction with implant usage led to a 5.7-fold increase in the median total cost in relation to non-reconstructed hemipelvectomies. The implant requirement was responsible for only $10 \%$ of this increase, whereas hospital stay and surgical costs contributed $26 \%$ and $19 \%$ to the total cost, respectively.

\section{DISCUSSION}

Pelvic bone tumors have varying sizes, affecting different regions, organs and other soft tissues. This large variety of presentations makes challenging the surgical resection, and hampers the comparisons between surgical strategies. Large series with sufficient power to address these issues are quite rare. ${ }^{3}$ Several techniques are used to reconstruct the disrupted pelvic ring ${ }^{5,7,10}$ and the flail hip joint ${ }^{1,11}$ and are associated with increased infection rates. Although, the surgical reconstruction is based on the disruption of the iliac ring and the support for the affected lower limb, ${ }^{12,13}$ these two factors are not considered by in the Enneking and Dunham classification. ${ }^{9}$ Many aspects of bone reconstruction remain unknown, such as the need for pelvic ring or acetabular reconstruction, the impact of prosthesis or allograft implantation on the infection rate and patients' functionality. Moreover, the prevalence and results of these varying surgical characteristics may have consequences in the hospital costs which were the objectives of this study.

The reconstruction of the pelvic ring is recommended to maintain the limb length and provide mechanical support for the preserved

\begin{tabular}{c|c|c}
\multicolumn{3}{|c}{ Table 3. Hospital costs and cost increase for different outcome groups. } \\
\hline & Total & \\
\hline Complication & & \\
\hline No & $7,845.79$ & 4.8 \\
\hline Yes & $37,823.73$ & \\
\hline Infection & & \\
\hline No & $9,131.02$ & 5.9 \\
\hline Yes & $54,206.61$ & \\
\hline Death & & 2.1 \\
\hline No & $10,264.74$ & 3.0 \\
\hline Early & $21,967.08$ & \\
\hline Late & $30,590.12$ & \\
\hline Implant & & 5.7 \\
\hline Without implant & $10,264.74$ & \\
\hline With implant & $58,890.755$ & \\
\hline
\end{tabular}

Table 2. Counts and proportions of implants and transplants used for reconstruction

\begin{tabular}{|c|c|c|c|c|c|c|c|c|c|c|c|}
\hline \multirow[b]{2}{*}{ No infection } & \multicolumn{2}{|c|}{ None } & \multicolumn{2}{|c|}{ Reconstruction } & \multirow[t]{2}{*}{ Prosthesis } & \multirow[t]{2}{*}{ Prosthesis + mesh } & \multirow{2}{*}{\begin{tabular}{|c|} 
Fibular graft \\
1 \\
\end{tabular}} & \multirow[t]{2}{*}{$\begin{array}{c}\text { Fibular graft + } \\
\text { Polypropylene mesh } \\
\end{array}$} & \multirow[t]{2}{*}{$\begin{array}{c}\text { Polypropylene } \\
\text { mesh }\end{array}$} & \multicolumn{2}{|c|}{ Total } \\
\hline & 19 & $(86 \%)$ & 1 & $(11 \%)$ & & & & & & 20 & $(65 \%)$ \\
\hline Infection & 3 & $(14 \%)$ & 8 & $(89 \%)$ & 2 & 2 & & 1 & 3 & 11 & $(35 \%)$ \\
\hline Total & 22 & $(100 \%)$ & 9 & (100\%) & 2 & 2 & 1 & 1 & 3 & 31 & $(100 \%)$ \\
\hline
\end{tabular}

Polyp = Polypropylene 
acetabulum. ${ }^{2}$ lliosacral arthrodesis with autograft, allograft, prosthesis or a combination of the three have been reported. ${ }^{13}$ Apposition of the remaining iliac bone to the sacrum is the easiest reconstruction technique and can be performed when the distance between both bones is small. ${ }^{13,14}$ For larger resections, Müller et al. ${ }^{8}$ suggested the use of megaprosthesis. Hillmann et al. ${ }^{12}$ recommended vascularized fibular grafts. ${ }^{12}$ It has been suggested that the reconstruction of the pelvic ring provides improved gait scores in comparison with non-reconstruction. ${ }^{10}$ For resected acetabulum, the hip support can be restored by arthrodesis, ${ }^{14}$ prosthesis, autograft, or hip transposition (Figure 1), improving the pelvic stability, load bearing, and reducing the limb length discrepancy. Prosthetic reconstruction is commonly related to increased loosening and infection rates. ${ }^{2,3,13,14}$ Gebert et al. ${ }^{11}$ reported good results with a low infection rate of 3 in 17 patients subjected to medialization of the hip with femoral endoprosthesis implantation. Barrientos-Ruiz ${ }^{15}$ had 10 wound and 2 deep infections in ten ice-cream-cone prosthesis implantations. Zeifang et al. ${ }^{5}$ suggested that biological reconstruction should be performed in younger patients, providing better longstanding functional results, whereas in older patients, endoprosthetic reconstruction should be preferred because of lower complication rates.

Deep infection, flap necrosis and implant loosening are the most frequent complications. The infection rate ranges from $10 \%$ to $50 \%$ and may demand multiple surgical debridements and soft tissue reconstructive procedures. $2,3,8,11,12,16$ Longer operative time and increased complexity are associated with higher wound infection and flap necrosis rates. ${ }^{4}$ Hip transposition was associated with a infection rate of $29 \% .{ }^{11}$ Angelini et al. ${ }^{3}$ reported an infection rate of $15 \%$ and $26 \%$ for non- and reconstructed hemipelvectomies, with a cure rate after one year of $87 \%$. In our study, the rate of infection was $36 \%$, with a resolution rate of $91 \%$ in 6 months. Infection was associated with implant use for bone reconstruction. As described by other authors, the histological grade of the tumor, previous surgery and previous radiotherapy were not associated with infections or complications., ${ }^{3,411}$ Hospital cost varied enormously. Hospital stay was responsible for almost $53 \%$ of costs. Surgery costs corresponded to $27 \%$ of costs, and implant cost was responsible for only $4 \%$. The onset of complications and infections caused a 4.8- and 5.9-fold cost increase, respectively, and prolonged the hospital stay from 7 days to 38 days and 9 days to 40 days, respectively. Similar studies showed that a prolonged hospital stay and the use of expensive medication increased total knee prosthesis revision costs in the United States. Infected and non-infected revisions were 3 to 4 times and two times more expensive in comparison with primary arthroplasties. ${ }^{17}$ In the United Kingdom, hospital stays for revisions of infected knee arthroplasties and the associates costs are more than twice as long and three times as high as those of aseptic revisions. ${ }^{18}$

The main limitation of this study is the small sample size due to the rarity of pelvic tumors. However, a larger series has shown similar results. Cost analysis is very particular to each country because of different health politics and financial support. Even inside Brazil, regional differences influence the hospital costs. The most important conclusion of our study is that bone reconstruction and the consequent prolongation of the operative time are important factors that increase short-term complication and infection rates and, consequently, hospital stays and costs. All of which can be avoided by performing less complex reconstruction procedures. Further studies should analyze whether complex reconstructions have a better functionality and quality of life that compensate for this high complication rate.

In conclusion, age, pelvic organ involvement, tobacco use, bone reconstruction and operative time were associated with complication rate increases in hemipelvectomy surgery. The infection rate was significantly higher for acetabular resections, bone reconstructions and longer operative time. The onset of complications in hemipelvectomies induced a 4.2-fold increase, and the onset of infection induced a 5.9-fold increase in hospital costs.

\section{FUNDING}

FAEPA (The Research, Teaching and Assistance Foundation of the Clinical Hospital of the Ribeirão Preto Medical School HC-FMRPUSP) supported this study.

\section{ACKNOWLEDGMENTS}

The authors thank Gislaine R. G. Belloube for the assistance with the collection of cost data.

AUTHORS' CONTRIBUTIONS: Each author contributed individual and significantly to the study development. MTB and AMH collected and analyzed the patient data and helped to define the study design. NFG and EEE operated on and followed the patients and interpreted the patient data. EEE (0000-00024047-2796)* and DAM (0000-0002-3893-0292)* analyzed the data and wrote the manuscript. All authors read and approved the final manuscript. *ORCID (Open Researcher and Contributor ID).

\section{REFERENCES}

1. Jaiswal PK, Aston WJS, Grimer RJ, Abudu A, Carter S, Blunn G, et al. Peri-acetabular resection and endoprosthetic reconstruction for tumours of the acetabulum. J Bone Joint Surg Br. 2008;90(9):1222-7.

2. Mayerson JL, Wooldridge AN, Scharschmidt TJ. Pelvic resection: current concepts. J Am Acad Orthop Surg. 2014;22(4):214-22.

3. Angelini A, Drago G, Trovarelli G, Calabrò T, Ruggieri P. Infection after surgica resection for pelvic bone tumors: An analysis of 270 patients from one institution tumor. Clin Orthop Relat Res. 2014;472(1):349-59.

4. Senchenkov A, Moran SL, Petty PM, Knoetgen J, Clay RP, Bite U, et al. Predictors of complications and outcomes of external hemipelvectomy wounds: account of 160 consecutive cases. Ann Surg Oncol. 2008;15(1):355-63.

5. Zeifang F, Buchner M, Zahlten-Hinguranage A, Bernd L, Sabo D. Complications following operative treatment of primary malignant bone tumours in the pelvis. Eur J Surg Oncol. 2004;30(8):893-9.

6. Kralovec ME, Houdek MT, Andrews KL, Shives TC, Rose PS, Sim FH. Prosthetic Rehabilitation After Hip Disarticulation or Hemipelvectomy. Am J Phys Med Rehabil. 2015;94(12):1035-40.

7. Bruns J, Luessenhop SL, Sen GD. Internal hemipelvectomy and endoprosthetic pelvic replacement: Long-term follow-up results. Arch Orthop Trauma Surg. 1997;116(1-2):27-31.

8. Müller PE, Dürr HR, Wegener B, Pellengahr C, Refior HJ, Jansson V. Internal hemipelvectomy and reconstruction with a megaprosthesis. Int Orthop. 2002;26(2):76-9.

9. Enneking WF, Dunham WK. Resection and reconstruction for primary neoplasms involving the innominate bone. J Bone Joint Surg Am. 1978;60(6):731-46.
10. Deneno BP, Gonçalves JCB, Lopes A, Brandalise SR. Resultado funcional em crianças e adolescentes submetidos à hemipelvectomia interna tipo II com ou sem reconstrução do anel pélvico. Rev Bras Ortop. 2007;42(5):125-32.

11. Gebert C, Wessling M, Hoffmann C, Roedl R, Winkelmann W, Gosheger G, et al. Hip Transposition as a Limb Salvage Procedure Following the Resection of Periacetabular Tumors. J Surg Oncol. 2011;103(3):269-75.

12. Hillmann A, Hoffman C, Gosheger G, Rödl R, Winkelmann W, Ozaki T. Tumors of the pelvis: Complications after reconstruction. Arch Orthop Trauma Surg 2003;123(7):340-4

13. Hugate R, Sim FH. Pelvic reconstruction techniques. Orthop Clin North Am. 2006;37(1):85-97.

14. Gerrand $\mathrm{CH}$, Bell RS, Griffin AM, Wunder JS. Instability after major tumor resection: Prevention and treatment. Orthop Clin North Am. 2001;32(4):697-710.

15. Barrientos-Ruiz I, Ortiz-Cruz EJ, Peleteiro-Pensado M. Reconstruction After Hemipelvectomy With the Ice-Cream Cone Prosthesis: What Are the Short-term Clinical Results? Clin Orthop Relat Res. 2017;475(3):735-41.

16. Ogura K, Miyamoto S, Sakuraba M, Chuman H, Fujiwara T, Kawai A. Immediate soft-tissue reconstruction using a rectus abdominis myocutaneous flap following wide resection of malignant bone tumours of the pelvis. Bone $\mathrm{Jt} J$. 2014;96 B(2):270-3.

17. Hebert CK, Williams RE, Levy RS, Barrack RL. Cost of treating an infected total knee replacement. Clin Orthop Relat Res. 1996;(331):140-5.

18. Kallala RF, Ibrahim MS, Sarmah S, Haddad FS, Vanhegan IS. Financial analysis of revision knee surgery based on NHS tariffs and hospital costs Does it pay to provide a revision service? Bone Jt J. 2015;97-B(2):197-201. 